\title{
Effectiveness Collagenase Injection in the Treatment of Patients with Dupuytren Systematic Review
}

\section{Cobo-Molinos Jesús ${ }^{{ }^{*}}$ and Cobo-Molinos Antonio ${ }^{2}$}

${ }^{1}$ Neurotraumatológico Hospital Complex of Jaén, Spain

${ }^{2}$ Department of Health Sciences, University of Jaen, Hospital of Jaen, Spain

*Corresponding author: Cobo-Molinos Jesús, Neurotraumatológico Hospital Complex of Jaén, Spain, Tel: +34953212121; E-mail: cobojesus@yahoo.es Rec date: Oct 14, 2016; Acc date: Nov 05, 2016; Pub date: Nov 07, 2016

Copyright: (C) 2016 Jesús CM, et al. This is an open-access article distributed under the terms of the creative commons attribution license, which permits unrestricted use, distribution, and reproduction in any medium, provided the original author and source are credited.

\begin{abstract}
Objetive: The purpose of this systematic review was to examine the scientific evidence found to determinate the effectiveness of collagenase injection in the treatment of Dupuytren's contracture.

Materials and methods: It was done through a literature search in 3 databases: PubMed, Scopus and PEDro. It was located 102 studies but only 8 clinical trial were selected because they fulfilled the criteria of inclusion and exclusion. Every clinical trial was assessed with PEDro scale.

Results: In the 8 studies had a significant improvement of contracture in the patients who had an injection collagenase. The improvement is similar to proximal interphalangeal joint to Metacarpophalangeal joints.

Conclusions: Despite the lack of studies about the effectiveness of this new treatment method, based on the chosen for our study we can say that the technique of collagenase can be effective in reducing the contracture caused by Dupuytren's disease.
\end{abstract}

Keywords: Dupuytren; Collagenase; Clostridium histolyticum collagenase; Genetic disease; Small painless nodule

\section{Introduction}

Dupuytren's disease is a clinical entity originally described over 400 years ago. Despite more than a century since its description by the physician Guillaume Dupuytren (1831), currently many jobs related to this disease, and assessing the multiple risk factors that exist to have this condition are performed. Find predisposing cause, or trigger the development of the disease is still unknown [1].

Dupuytren's disease is a progressive, genetic disease. Fibroproliferative disorder involves shortening and thickening of the palmar fascia, leading to contracture of permanent and irreversible bending of the digits $[2,3]$.

The disease often begins with a small painless nodule in the connective tissue (fascia) of the palm that eventually becomes a band cord-preventing full extension of the finger. Normal fascial bands and ligaments become contractile, becoming diseased tissue called cords or nodules [4]. This transformation leads to joint contracture, stiffness and decreased mobility of skin and fascial tissue, significantly distorting surrounding anatomical structures [2].

These reflections that predominantly affects the fourth and fifth finger and due to the proliferation of myofibroblasts in the fascia of the hand [5].

Although in 1881 described how permanent shrinkage due to a related contracture of the palmar fascia, today disease is known which may be closely related to other diseases such as rheumatism, gout, alcohol and snuff, diabetes mellitus, use of AEDs, local lesions (leading to Reflex sympathetic dystrophy), hand disuse affecting minor trauma caused by a trade such as bricklayers, carpenters or miners [6,7].

\section{Population Studies}

This disease is not a very common condition as observed in studies, affects $3 \%$ to $6 \%$ of the general population and is more common in countries of northwestern Europe. A curious fact that this serious disease is also found in countries such as Japan (where prevalence is similar to that observed in Northern Europe) while it occurs less frequently in African American patients. The authors compared these results have postulated in response, a previous interracial mixing in the genetic lineage of affected individuals. Geographically, it is more common in the UK, Scandinavia, North America, Australia and Japan, with a marked decrease in prevalence in Mediterranean regions further south and South America. Being rare in Africa and Asia [7].

If we now analyze the affected Dupuytren about sex population, the prevalence of the disease is $9.4 \%$ for men and $2.8 \%$ for women [8]. In the case of men, the disease became more noticeable after 50 years and a decade later in the case of women. With regard to children, rarely, children under 9 years have been diagnosed with the disease [7].

For decades, several authors maintained that the disease came generated by the occupation of the patient, however, currently has not appreciated association between occupation and the risk of developing the disease. Have reviewed all of the work, a priori, had methodological minimum quality standards, being only association to disease in those works completely manually or using machinery with vibration. It notes that most countries do not recognize this condition in the group scope of occupational diseases; in Spain is not included 
within occupational diseases, in the section on physical agents, as set out in R. D. 1995/1978 (BOE 25/8/1,978) [6].

Another group of candidate population suffer serious disease burden those with genetic disease with variable expression in terms of race and gender. However, the observed genetic transmission (autosomal dominant) is compatible with a dominant gene of variable penetrance [9].

\section{Clinic}

The evolution of the disease is variable regarding the initiation and progression of lesions; is a phase beginning with presentation of subcutaneous nodules or not even in general, the extension of the metacarpophalangeal preserved

Natural course of progression causes, over time, the deformation phase in which the lesions are worsened and palmar digital display arise; palmar level to appear flexo deformities of the metocarpofalángicas with inability to passively correct. There may also be nodes in the proximal phalanx starting progressive retraction of the proximal interphalangeal. When the deformity is already established, this default extension is offset by the hyperextension of the distal interphalangeal boutoniere causing deformity.

Although not uniformly regulate or evolution; lesions may remain stable or deteriorate rapidly. It has been observed that the onset of the disease, bilateral involvement, the presence of dorsal pads and family background have a positive correlation with the speed of evolution [10].

\section{Diagnosis}

The existence of a tendon section is suspected when the skin wound is positioned over the path of tendon observed anomalous position relative to the finger should be presented in a rest position by the viscoelastic muscle tension. When the two flexor tendons of a finger are disabled, it remains in a natural position hyperextension when compared with uninjured fingers. The flexor tendon injury can be confirmed by several maneuvers passive mobilization. Passive wrist extension does not produce the usual bending tenodesis fingers. If the wrist flexes, hyperextension not counteracted even more of the affected finger occurs.

Tendon function is most often assessed with active exploration. the patient to flex the fingers clenching his fist is requested; if the distal interphalangeal joint is not flexed, it indicates deep flexor tendon injury. Exploring the superficial tendons must be done individually for each finger [11].

\section{Treatment}

\section{Nonsurgical treatment}

Medical treatment: It is not effective at present; conservative treatments have been tried with different drugs such as vitamin A or vitamin $\mathrm{E}$ but the results have been unsatisfactory as they have transient results.

Recently advocated, based on in vitro studies, the use of enzymatic fasciotomy with purified collagenase from Clostridium histolyticum, although this therapy is under clinical trial.
Aponeurotomy needle: It is performed under local anesthesia, using the mechanical action of a hypodermic bezel to break the flange percutaneously both palmar digital level as needle. The results, in stage I and II and in children under 60 years are often similar to short and long term, to those obtained through surgical aponeurotomy.

Continuous extension technique: It involves placing an internal fixator in the retracted radius, exerting a progressive traction on the finger; today, it is proposed as a pretreatment for surgery in severe digital retractions, constituting an alternative to amputation.

\section{Surgical treatment}

In general, surgery is indicated once contracture has increased to $>30$ degrees for joints MF and $>15$ degrees for PIP joints with the identification of a palpable cord [12]

Different surgical procedures can address multiple joints affected in the same hand and usually have good results, but there can be complications of surgery, such as nerve damage or artery. In particular, the length of recovery time needed to return to daily activities after surgery is of concern for many patients [12].

Aponeurotomy: The symptomatic treatment par excellence. Is the cross section of the aponeurotic structures retracted (flange) by one or more small incisions staggered without removing the affected aponeurosis; It is a limited surgery that removes the tension in the aponeurosis but does not prevent recurrences and is reserved for elderly patients and carriers of a single flange, without shrinkage joints.

Aponeurectomías: Resection of macroscopically identifiable fascial formations is performed; it may be a limited, regional or selective aponeurectomy in the palm, limiting the sector injured palmar aponeurosis or a wide, full or radical aponeurectomy, consisting of extending the palmar resection to bandeletaspretendinosas, apparently healthy, with intent to prevent extension of Dupuytren's disease at that level. Currently, the regional aponeurectomy which is limited to the affected tissues is preferred.

\section{Collagenase treatment}

Collagenase is an enzyme derived from the bacterium Clostridium hystolyticum. Currently it used as a treatment injected directly into the diseased tissue, and the affected digit is passively stretched a day after the intervention [13]. Such non-surgical maneuver involves injecting a small volume (metacarpophalangeal strings, $0.25 \mathrm{ml}$, interphalangeal proximal strings, $0.20 \mathrm{ml}$ ) of collagenase solution [14].

This injection technique collagenase has also been used in other treatments such as debridement of burns or ulcers and in the treatment of Peyronie's disease. Studies of Starkweather, Badalamente and Hurst authors have been instrumental in the investigation of collagenase as a potential therapeutic agent for Dupuytren's disease (Table 1).

Clostridium histolyticum collagenase $(\mathrm{CCH})$ acts on the degradation of type I and III collagen via two different subtypes of enzymes belonging to the group of metalloproteases. Currently, the use of this enzyme shows favorable clinical results after administration, with rates of improvement in $70 \%$ to $90 \%$ of cases. The safety profile is extensive, and often described certain disorders in the form ecchymosis or even small openings in the skin at the injection site in the soft tissues of the hand. Since its approval for marketing in Europe in February 2011, its use as an alternative for Dupuytren's contracture 
Citation: Jesús CM, Antonio CM (2016) Effectiveness Collagenase Injection in the Treatment of Patients with Dupuytren Systematic Review. J

Page 3 of 7

has shown advantages of non-invasive treatment (rapid recovery, low complication rate and minimal disruption of the skin) [15].

\begin{tabular}{|c|c|c|c|c|c|c|c|c|c|c|c|}
\hline Studies & $\begin{array}{l}\text { Random } \\
\text { assignm } \\
\text { ent }\end{array}$ & $\begin{array}{l}\text { alloca } \\
\text { tion } \\
\text { conce } \\
\text { aled }\end{array}$ & $\begin{array}{l}\text { homo } \\
\text { geneo } \\
\text { us } \\
\text { group } \\
\mathbf{s}\end{array}$ & $\begin{array}{l}\text { blindi } \\
\text { ng } \\
\text { partici } \\
\text { pants }\end{array}$ & $\begin{array}{l}\text { blindi } \\
\text { ng } \\
\text { therap } \\
\text { ists } \\
\mathrm{S}\end{array}$ & $\begin{array}{l}\text { blinding } \\
\text { assesso } \\
\text { rs }\end{array}$ & $\begin{array}{l}\text { adequate } \\
\text { monitorin } \\
\mathrm{g}\end{array}$ & $\begin{array}{l}\text { Intention } \\
\text { to treat } \\
\text { analysis }\end{array}$ & $\begin{array}{l}\text { Comparison } \\
\text { of results } \\
\text { between } \\
\text { groups }\end{array}$ & $\begin{array}{l}\text { Specific } \\
\text { measurements } \\
\text { of variability }\end{array}$ & Total (out of 10) \\
\hline Hurst et al. [18] & NO & YES & YES & NO & NO & NO & YES & NO & YES & YES & $6 / 10$ \\
\hline Cuervo et al. (2014) & NO & YES & NO & NO & NO & NO & YES & NO & YES & YES & $4 / 10$ \\
\hline $\begin{array}{l}\text { Martín Ferrero et al. } \\
\text { [20] }\end{array}$ & NO & YES & NO & NO & NO & NO & YES & NO & YES & YES & $4 / 10$ \\
\hline Hayton et al. [21] & NO & YES & YES & NO & NO & NO & YES & NO & YES & YES & $5 / 10$ \\
\hline Coleman et al. [12] & NO & YES & NO & NO & NO & NO & YES & NO & YES & YES & $4 / 10$ \\
\hline $\begin{array}{l}\text { Bainbridge et al. } \\
\text { [22] }\end{array}$ & NO & YES & NO & YES & NO & YES & YES & NO & YES & YES & $6 / 10$ \\
\hline $\begin{array}{l}\text { Coleman et al. } \\
\text { (2013) }\end{array}$ & NO & YES & NO & NO & NO & NO & YES & NO & YES & YES & $4 / 10$ \\
\hline
\end{tabular}

Table 1: Scale Pedro.

Collagenase has proven to be a non-invasive and safe surgical alternative release of the contracture; however, the results, the recurrence rate, and high cost have led surgeons to wonder whether collagenase is sustainable treatment. This treatment is still a relatively new treatment option, and although the literature on the clinical success is somewhat limited, should be considered an alternative when surgery is not an option [16].

\section{Material and Methods}

\section{Search strategies}

Databases information sources: The search was conducted in the databases PubMed, Scopus and Peter during the months of February to April 2015. In all databases they have been used the same keywords (MeSH terms). These were "Dupuytren", "collagenase" and "Clostridium histolyticum collagenase." Since the aim to study the effect of collagenase on Dupuytren's disease, it was combined with others. In all databases, the same type of search was performed with these terms MeSH.

\section{Inclusion criteria:}

- Language: Studies found in English or Spanish were selected

- Type intervention: Those trials where the effect of injection of collagenase in patients suffering Dupuytren's disease was studied were selected.

- Type patients: Patients were human, were aged above 18 years and should be diagnosed Dupuytren.

- Period publishing articles that had been published between 2005 and 2015 were chosen.

He selected trials whose full text was available.

Exclusion criteria: No systematic reviews, clinical cases, wireless studies, case series or descriptive studies are included. Studies comparing various techniques of surgical and nonsurgical treatment. trials that were not in the required languages were also eliminated.

\section{Evaluation of methodological quality of the studies}

The PEDro scale is a means to assess the quality of clinical trials and physiotherapy interventions helping turn to classify them in the database or PEDro (physiotherapy evidence database).

The scale consists of 11 items, of which only scored 10. Each item values aspects favoring the quality and validity of the test. It also assesses the correct inclusion of statistical information. The items are graded according to their presence or absence in the test are scored only positive responses.

Studies with a score greater than or equal to 5 have high methodological quality [17].

\section{Summary of Results}

\section{Study selection}

After searching for information in databases Cochrane, PubMed, Scopus and PEDro, a total of 102 articles which referred to the chosen topic found. Of these items were discarded based on the inclusion criteria, leaving the end 8estudios valid for review (Table 2).

\begin{tabular}{|c|c|c|}
\hline Databases used & Terms MeSH & Item numbers \\
\hline \multirow[t]{2}{*}{ PubMed } & $\begin{array}{l}\text { Dupuytren AND } \\
\text { Clostridium histolyticum } \\
\text { collagenase }\end{array}$ & 36 \\
\hline & $\begin{array}{l}\begin{array}{l}\text { Dupuytren } \\
\text { collagenase }\end{array} \quad \text { AND } \\
\end{array}$ & 35 \\
\hline \multirow[t]{2}{*}{ SCOPUS } & $\begin{array}{l}\text { Dupuytren AND } \\
\text { clostridium histolyticum }\end{array}$ & 0 \\
\hline & $\begin{array}{l}\text { Dupuytren } \\
\text { collagenase }\end{array} \quad$ AND & 30 \\
\hline PEDRO & $\begin{array}{l}\text { Dupuytren AND } \\
\text { clostridium histolyticum }\end{array}$ & 0 \\
\hline
\end{tabular}




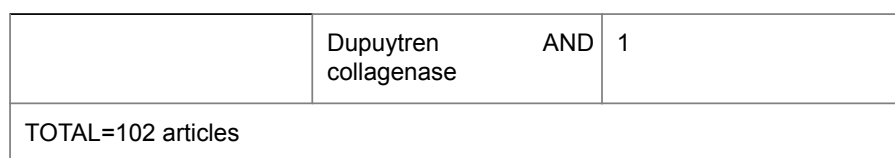

Table 2: Literature search results.

In PubMed a total of 71 articles of which 36 corresponds to the search with the terms "histolyticum collagenase clostridium and Dupuytren" and 35 "Dupuytren and collagenase" found. Of the 71 articles, only 48 were fully adjusted to the criteria and were selected for review. The remaining 23 were removed in more detail and to review them; They did not talk about it specifically, compared with other techniques not using collagenase or collagenase. Among the valid duplicate studies obtained four search with different terms being as a result 29 studies for review were eliminated.

Scopus a total of 30 articles, which correspond to the search with the keywords "Dupuytren and collagenase" found. Of the 30 articles, only 25 are fully adjusted to the criteria and were selected for review after reading the title and abstract. The remaining five were eliminated by not meeting the search criteria: not to talk about it, compare other techniques or discuss this technique in particular. Among the selected duplicate of the four searches resulting 6 items for review they were eliminated.

In PEdro only 1 item was found with the words "Dupuytren and collagenase", referring to the subject of our study, but was removed to find that it was duplicated other searches.

Cochrane two searches using keywords "Dupuytren and Clostridium histolycicum" and "Dupuytren and collagenase" were made, but did not find articles that made reference to the subject of our study.

In all the studies achieved the 3 databases were 35 items. Of all the items obtained, we again review and we are left with 22 items that are clinical trials, we eliminate the remaining 13 being studied descriptive of the different techniques of collagenase.

The next step was to discard items that have not had access to be paid, so we are left with 8 items for our study.

\section{Results}

In the 8 studies involved selected patients are diagnosed in the ED and are unable to place the affected finger and palm of the hand while on a flat surface. They will be subject to a system based on the injection of collagenase, to demonstrate the efficacy and safety of this treatment. Joint contractures were mediated by goniometry and had $20^{\circ}$ or more in flexion. In all studies they are over 18, and only in a study distinction between women and men for the results is made. the disease was classified according to the severity of the contracture. the ROM is also studied by goniometry, fixed flexion contracture and in some degree of patient satisfaction after the study. Clinical success appears as primary objective in all studies, and was defined as a reduction of joint contracture $\leq 5^{\circ}$ full extension 30 days after injection. All patients were assessed before and after treatment. It excludes the thumb in most studies.

Hurst LC et al studied the effect of collagenase in Dupuytren's disease on a double-blind, placebo-controlled, prospective, randomized, multicenter study [18]. Of the 308 patients; Collagenase received 204 joints and 104 received placebo. IFP or MCF joints of these patients were randomized to receive up to three injections of collagenase clostridium histolyticum (at a dose of $0.58 \mathrm{mg}$ per injection) was reconstituted in $0.25 \mathrm{ml}$ of sterile diluent (for the MCP joints) or $0.20 \mathrm{ml}$ of sterile diluent (for PIP joints) and injected directly into the affected cables or placebo $(10 \mathrm{mM}$ TRIS $60 \mathrm{mM}$ sucrose reconstituted in diluent) was administered in a similar manner on the cable at intervals contracted collagen 30 days. One day after injection, the joints were handled up to three times if necessary, using a standard procedure.

In general, the range of motion in joints was significantly improved after injection with collagenase compared to placebo. The most common adverse events were localized swelling, pain, bruising, itching and transient enlargement of regional lymph nodes and tenderness. two tendon ruptures and one case of complex regional pain syndrome: three serious adverse events related to treatment were reported. No significant in flexion or grip strength changes, no systemic allergic reactions were seen and no nerve damage. The primary endpoint was the reduction of contracture of 0 to 5 degrees of full extension 30 days after the last injection (Figure 1).

$\mathrm{RB}$ et al Raven conducted a secondary data analysis of data pooled from 3 randomized subgroups, double-blind, phase 3 placebocontrolled clinical trials [19]. This study tested the safety and efficacy of treatment CCH Dupuytren's disease. The studies were conducted in 17 study centers in the United States and five centers in Australia. The affected joints were classified according to the severity of the contracture;

This analysis included 271 patients who were treated with at least 1 dose of $\mathrm{CCH} ; 167$ with involvement of the MCF and 104 articulation with IFP affected joint. The degree of joint contractures were greater than or equal to 20 degrees and treated with $\mathrm{CCH}(0.58 \mathrm{mg}$ collagenase injection). The subjects were matched by sex, age $(<$ or $>65)$, and the state of the patient's diabetes. Patients were randomized to receive either $0.58 \mathrm{mg}$ or placebo $\mathrm{CCH}$. Only they were included in this analysis patients treated with $\mathrm{CCH}$. In patients treated with $\mathrm{CCH}, 63 \%$ of patients achieved clinical success for joint MCF and IFP, 76\% for MF joints, and $42 \%$ for PIP joints. In the vast majority of patients receiving $\mathrm{CCH}$ injection (98\%) experienced at least one adverse event, most of which were local and resolved without intervention. 6 most common adverse events ( $>25 \%$ ) were peripheral edema (swelling of the treated hand), bruising, injection site pain, and pain in the upper extremities.

In the period between 2011 and 2013, Martin Ferrero et al. conducted a prospective study, which evaluated the clinical variables as well as the functionality and safety of the patients own after injecting $\mathrm{CCH}$ [20]. 35 right-handed patients for the study, affected by Dupuytren's disease were included, all men aged between 45 and 89 years. They were taken to the University Hospital of Valladolid. 15 patients were treated left hand and right hand 20 patients. Headquarters finish the severity of the disease by classifying Tubiana. Of the 35 patients; 22 were injected into a single palpable cord at the level of the MCF, 6 patients were injected into the rope and affecting two fingers, 5 patients treated by injection of the rope at the level of IFP and 2 patients underwent puncture bend at the MCF and IFP.

Inclusion criteria were patients with Dupuytren's disease, with a palpable cord in at least one finger excluding the thumb contracture of at least $20^{\circ}$ to $90^{\circ}$ at the level of the MCF and $80^{\circ}$ in the IFP. And finger extension cord break was held at $24 \mathrm{~h} \mathrm{CCH}$ has been injected. The index of the MCP joint contracture was the beginning of 64 th this improvement after track after injection resulting only 4 th at 6 months 
Page 5 of 7

in the group of pre-puncture IFP was $83.3^{\circ}$ and $15^{\circ}$ in the review of the 2,3 and 6 months.

Contracture index finger in the group of $\mathrm{MCF} /$ puncture prior IFP was $140^{\circ}$ and after puncture was $20^{\circ}$ at 3 and 6 months. In 9 patients occurred during stretching of dehiscence finger resolved without complications, 13 patients had hematoma at the puncture site, 2 patients with axillary lymph node qus was resolved in 48 hours and two increased transaminases patients without clinical consequences. Quick and painless functional recovery, only 3 patients required physical therapy.

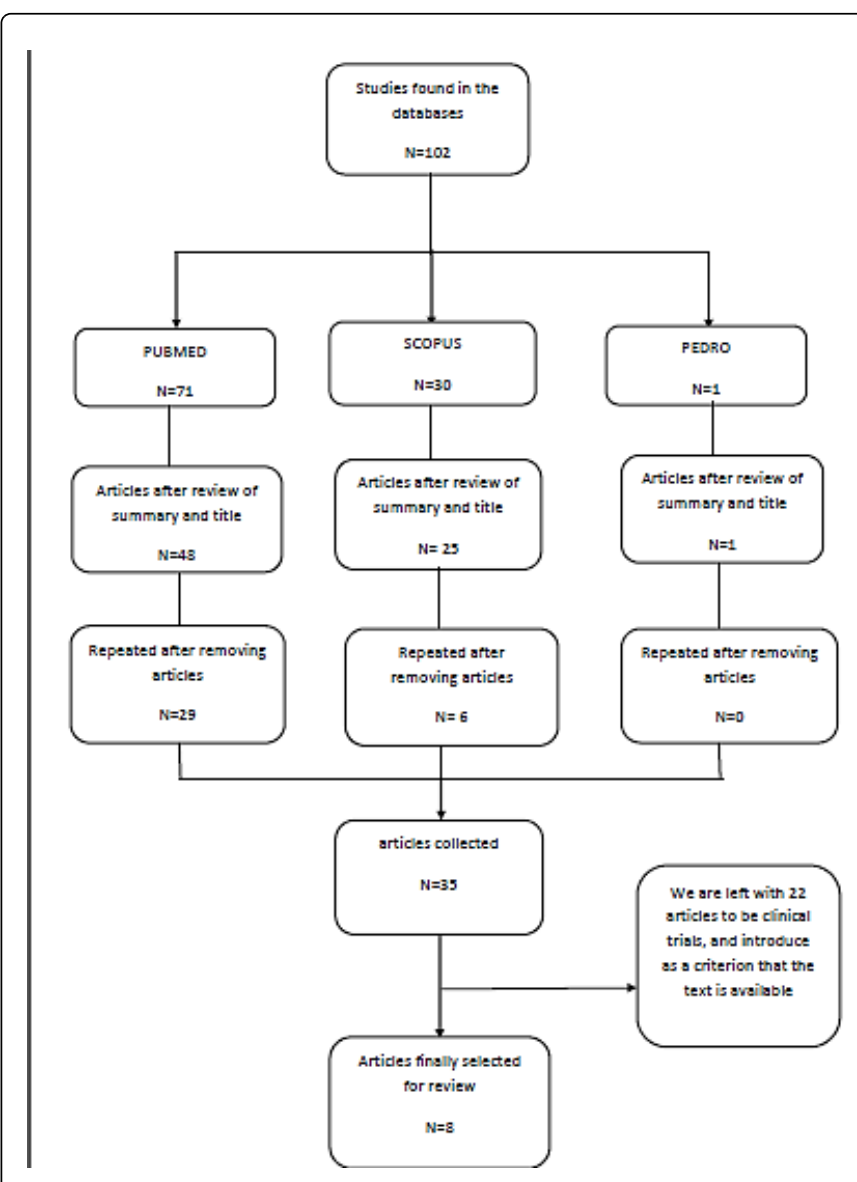

Figure 1: Flow chart.

Hayton et al. conducted an exploratory study to determine the effectiveness of $\mathrm{CCH}$ in Dupuytren [21]. The study was conducted in the US, Europe and Australia. Patients may receive up to three injections during the study period. The endpoints include correcting and improving contracture. Fixed flexion contracture (FFC) and range of motion (ROM) were also evaluated; adverse events. In total, 616 patients were included in the analysis. Data from two patient subgroups were analyzed. In Group A, patients had contractures MCF and IFP on the same finger, but only affects the cable joint MCF treated with $\mathrm{CCH}$. In group $\mathrm{B}$, patients had a joint contracture isolated IFP (IFP or joint contracture combined with joint contracture MCF $<20^{\circ}$ ), and only the cable affecting the PIP joint was treated with $\mathrm{CCH}$. In Group A, 28 and $43 \%$ of contractures in the PIP joints were corrected spontaneously after the first and the last injection of $\mathrm{CCH}$ for MCF; 40 and 63\%, respectively, improved. In Group B, 31 and 39\% of
IFP joint contractures were corrected after the first and the last injection of $\mathrm{CCH}$; 56 and 66\%, respectively, improved. In groups $\mathrm{A}$ and $\mathrm{B}$, improvements FFC was larger after the last injection; ROM was larger improvements after the last injection in Group A and third injection in Group B. For 46 and $44 \%$ of patients in Groups A and B, respectively, the first injection was the last injection. Almost all patients (98\%) experienced at least one adverse event; reactions were most injection site.

Coleman et al. through an open pilot study at a single center of Australia to examine the safety, efficacy and pharmacokinetics of multiple doses of injection of two affected joints with multiple doses of $\mathrm{CCH}$ simultaneously in the same hand in subjects with ED and multiple contractures [12]. Patients had to have a diagnosis of ED with at least three fixed contractures caused by palpable cords or MCF IFP fingers (not thumb). The patients were unable to put fingers and palm while on a surface.

They were selected 12 subjects for the study, the average age of 64 . Of the subjects six had a family history of ED, five had previously undergone surgical correction, but the other seven had not received any treatment. In the course of the study they were treated MCF 22 and 14 IFP. Of the 12 subjects 8 had joints treated in different hands during the treatment period 1 and 2 , while 4 patients were treated joints in the same hand, but on different fingers. In period 1 the average reduction was $29.0 \pm 20.7$ degrees in the MCP joints and 30.7 \pm 21.1 degrees in the PIP joints. The range of motion increased in both joints during the period 1 . In period 2 , the mean reduction in contracture of the baseline $30.3 \pm 10.9$ degree and 22.1 $\pm 4.9 \mathrm{MCF}$ degrees IFP. In period 2 with respect to the range of motion in joints it increased MCF and IFP. Adverse events related to the most common treatment that occurred during the study were all local events and include some degree of peripheral edema. There were three adverse events,

Bainbridge et al. performed four randomized, double-blind, placebo-controlled centers of Australia; the remaining eight were designed as open trials [22]. Eligible patients were older than 18, were in good health and were unable to simultaneously place the finger affection and palm on a flat surface. The researchers before the study classified the joints in low or high severity. The endpoints included changes in fixed flexion contracture and range of motion. Adverse events were monitored Patients may receive up to $3 \mathrm{CCH}$ injections at intervals of 30 days, double-blind trials and five cycles in open studies.

The data of 1082 patients who received the injection of $\mathrm{CCH}$ were analyzed and coded for patients and joints. 422 had had previous surgery patients (hand operated injection $n=206$, not hand operated injection $n=196$, and do not identify hand operated $n=20$ ) and 660 never had undergone surgical treatment. Among patients who had been operated on, there were differences between patients that $\mathrm{CCH}$ was injected into the patients operated hand and with the other hand. No significant differences between groups who had previous surgery and those who had not been obtained. However, rates of clinical success for MF and IFP were significantly higher among patients who had no previous surgery for patients. Similarly, changes in fixed flexion and range of motion were significantly higher in the group without previous surgery, Overall, $97 \%$ of patients reported having studied with some EA during treatment. In total, nine patients experienced 10 EAG probably related to treatment.

By an open phase III study, conducted in 8 European countries, to test the efficacy and safety of $\mathrm{CCH}$ injection in patients diagnosed with 
Dupuytren's disease [23]. Patients were older than 18 years and were unable to place the palm and finger affection while on a surface. Patients rated the joints they wanted were treated and were asked to provide a reason for this choice goniometry was used to assess the degree of overall passive finger extension, and range of motion. A total of 249 patients (98\%) completed the study. In total $52 \%$ and $4 \%$ of patients selected the pinkie and ring finger, middle finger $7 \%$ and $0.8 \%$ index finger for the first injection. Regardless of the finger treated, 79\% of patients had a MCPJ treated first; $21 \%$ had the PIP joint treated first. In general, joints 375 received an injection $\mathrm{CCH}$; Joints 66 and 15 received injections 2 and 3, respectively. The MCP joints showed reduced 30 days after injection, this was further improved after 90 days after injection. This improvement was maintained over the next six months. For joints IFP, changes in ROM were larger after the first injection, and this trend was maintained for 90 days after injection and six months. At baseline, $83 \%$ of patients and $80 \%$ of doctors classify the severity of Dupuytren as moderate or severe. These values were reduced $21 \%$ and $25 \%$ at day 90 and $30 \%$ and $27 \%$ at 6 month respectively. $88 \%$ or more experienced treatment-emergent adverse events. Almost all adverse events were mild or moderate in severity. Only 10 patients experienced serious adverse events.

Coleman et al. evaluated the safety and efficacy of two concurrent injections of $\mathrm{CCH}$ in the same hand to treat multiple flexion contractures caused by Dupuytren's disease [24]. They conducted a multicenter, phase IIIb open-label. It was conducted at 8 sites in the US and Australia between September 2011 and February 2012. Eligible patients were aged 18 years and had to be diagnosed with Dupuytren's disease with at least 2 flexion contractures in the same hand. one sample $\mathrm{n}=60$ patients, who were injected with both $\mathrm{CCH}$ in contractures of the same hand, followed by a manipulation after $24 \mathrm{~h}$ after treatment was chosen. There success on day 30 after the injection of $\mathrm{CCH}$ changes in flexion contracture and active range of motion, patient satisfaction and clinical success rates (5th flexion contracture or less). Simultaneous injections are most commonly administered in the wires that affect MCF E IFP on the same finger or two joints MCF in different fingers. The clinical success rate was $76 \%$ for joint MCF and 33\% for joints IFP. There was an increased incidence of adverse events compared with concurrent treatment with the treatment of a single joint.

\section{Discussion}

The objective of this review was to assess the effectiveness and safety of collagenase, noting a clinical and functional improvement, as well as a rapid recovery of the patient. Most patients may be candidates for treatment of collagenase, as many patients cannot undergo surgery or are not willing to undergo because of the surgical process and its risks, in addition to the long process of healing. In contrast to the art of collagenase it is not necessary. Surgery is also associated with more injuries than collagenase injection.

After reading and analyzing the 8 items that we have chosen for this study it was obtained that the collagenase technique is effective and well tolerated by the patient; in 6 articles the effectiveness of this is assessed at time intervals of 30 days between the possible injections, for the same or different joint and the remaining two items evaluate the results obtained using multiple injections in a simultaneous in the same or different contracture with time intervals 3 days maximum. The results suggest that single and multiple injections are equally tolerated.
Of the 8 items of the study in just 1 articles we have compared the data from the control data obtained in the placebo group. This improvement for the control group was much higher than for placebo in both ROM and decreased contracture. Here also asked the patient to carry a splint later, but the effectiveness of it for recurrence of the contracture was not assessed.

Hayton et al. evaluated the effectiveness of treating collagenase a VTI directly or through the MFC same finger joint. a proximal cable that can reduce some tension that affects the distal joints is released. The result of this is still positive for both methods, so you can use different treatment options to correct an IFP.

In most articles is shown that the effectiveness of collagenase is greater for the MCP joints that VTI, because the PIP joint is less sensitive to the intervention and are more susceptible to recurrence. Better results are also obtained for patients in which the degree of contracture is less 8 articles in talks about possible adverse effects that some patients have suffered studies, although all have been controlled in a short time. In 1 study relates that a greater number of simultaneous injections more likely to suffer but not more severe adverse effects. Raven third et al. explained in another article that found no difference in complications between the group of women and men, diabetics or the elderly. Bainbridge et al. says that patients who have undergone surgery by surgery and receive the injection of collagenase are more likely to suffer adverse effects than previously operated.

In any study talking safely recurrence of the contracture, since in most have not tracked long term after surgery. Just talking about a higher probability of recurrence in the PIP joint in a study that refers to other articles.

\section{Conclusion}

New studies deepen about the effects of this new technique long term as well as recurrence of the contracture because there are not enough quality studies, it is necessary.

Based on the articles analyzed, this review suggests that collagenase technique proves to be effective for improvement in contracture in patients diagnosed with Dupuytren's Disease.

It could eventually be used as early treatment to prevent the patient might become involved with surgery. This would imply a decrease in direct and indirect costs both (OR, priests, nurses), and even the time used for this intervention would decrease the waiting list, not only of this disease, also others that need surgery. To be available for hand movement, would be off work for less time could save 1,200 euros when an average of 1.5 injections per patient is administered.

\section{References}

1. Marble-Soler S, Mirror-Ortega L, Gutierrez-Ortega C, García-Rosado M, Valera-Nunez A, et al. (2013) Non-surgical treatment in Dupuytren's contracture with collagenase from Clostridium hystoliticum Cir plast. Iberolatinoam 39: 3 .

2. Black EM, Blazar PE (2011) Dupuytren disease: An evolving understanding of an age old-disease.J Am AcasOrthopSurg 19: 746-757.

3. Shib B, BayatA (2010) Scientific understanding and clinical managent of dupuytren disease. Nat Rev Rheumatol 6: 715-726.

4. Iqbal SA, Hayton MJ, Watson JS, Szczypa P, Bayat A (2014) First identification of resident and cirulationg fibrocytes in Dupuytren's disease shown to be inhibited by serum amyloid P and Xiapex. Plos one 9: e99967. 
Citation: Jesús CM, Antonio CM (2016) Effectiveness Collagenase Injection in the Treatment of Patients with Dupuytren Systematic Review. J

5. Mafi R, Hindocha S, Khan W (2012) Recent surgical and medical advances in the treatment of Dupuytren's disease: A systematic review of the literature. Open Orthop J 6: 77-82.

6. Rey Calero J (1992) Occupational diseases. Preventive medicine and public health (9thedn) Barcelona: Masson-Salvat Medicine.

7. Thomas A, Bayat A (2010) The emerging role of Clostridium histolyticum collagenase in the treatment of Dupuytren disease. Ther Clin Risk Manag 6: 557-572.

8. Yost J, Winters T, Fett HC (1955) Dupuytren's contracture a statistical study. Am J Surg 90: 568-711.

9. Lyall HA (1993) Dupuytren's disease in identical twins. J Hand Surg 18B 368-370.

10. Srinivasan RC, Shah AS, Jebson PJ (2010) New treatment options for Dupuytren's surgery: Collagenase and percutaneous aponeurotomy. 35: 1362-1364.

11. Delgado MA (2009) Traumatología. Madrid orthopedic surgery: Editorial Medica Panamericana.

12. Coleman S, Gilpin D, Tursi J, Kaufman G, Jones N, et al. (2012) Multiple concurrent collagenase clostridium histolyticum injections to dupuytren's cords: An exploratory study. BMC Musculoskelet Disord 13: 61.

13. Beredjklian PK (2011) 50 Years Ago in CORR: Dupuytren's contracture: A Guide for Management L. D. Howard MD CORR Clin Orthop Relat Res 469(1): 309-311.

14. Eaton C (2014) Evidence-based medicine: Dupuytren contracture. Plas Reconstr Surg 133: 1241-1251.

15. Sanjuan Cervero R, Franco Ferrando N, Poquet Jornel J (2013) Use of resources and costs associated with the treatment of Dupuytren's contracture at an orthopedics in Denia(Spain): collagenase clostridium histolyticum versus subtotalfasciectomy. BMC Musculoskelet Disord 14 293.

16. Sood A, Therattil P, Paik AM, Simpson MF, Lee ES (2014) Treatment of Dupuytren disease with injectable collagenase in a veteran population: A case series at the department of veterans affairs New Jersey health care system. Eplasty 14: e13.
17. Moseley AM, Herbert RD, Sherringtong C, Maher CG (2002) Evidence for physiotherapy practice: a survey of the Physiotherapy Evidence Database (PEDro). Aust J Physiother 48: 43-49.

18. Hurst LC, Badalamente MA, Hentz VR, Hotchkiss RN, Kaplan FT, et al. (2009) Injectable collagenase clostridium histolyticum for Dupuytren's contracture. N Engl J Med 361: 968-979.

19. Raven RB, Kushner H, Nguyen D, Naam N, Curtin C (2014) Analysis of efficacy and safety of treatment with collagenase Clostridium histolyticum among subgroups of patients with Dupuytren contracture. Ann Plast Surgery 73: 286-290.

20. Martín Ferrero MA , Simón Pérez C , Rodríguez Mateos JI, García Medrano B, Ramajo HR, et al. (2013) Treatment of Dupuytren's disease using collagenase from Clostridium histolyticum. Rev Esp Cir Ortop Traumatol 57: 398-402.

21. Hayton MJ, Bayat A, Chapman DS, Gerber RA, Szczypa PP (2013) Isolated and spontaneous correction of proximal interphalangeal joint contractures in Dupuytren's disease: An exploratory analysis of the efficacy and safety of collagenase Clostridium histolyticum. Clin Drogas Investig 33: 905-912.

22. Bainbridge C, Gerber RA, Szczypa PP, Smith T, Kushner H, et al. (2012) Efficacy of collagenase in patients who did and did not have previous hand surgery for Dupuytren's contracture. J Plast Surg Hand Surg 46: 177-183.

23. Warwick D, Arner M, Pajardi G, Reichert B, Szabo Z, et al. (2015) Collagenase clostridium histolyticum in patients with Dupuytren's contracture: results from POINT X, an open-label study of clinical and patient-reported outcomes. J Hand Surg Eur 40: 124-132.

24. Coleman S, Gilpin D, Kaplan FT, Houston A, Kaufman GJ, et al. (2014) Efficacy and safety of concurrent collagenase clostridium histolyticum injections for multiple Dupuytren contractures. J Hand Surg Am 39: 57-64. 